\title{
Hypocholesterolemic and angiotensin i converting enzyme-inhibiting activity of trypsin-hydrolysed bovine casein
}

\begin{abstract}
Nowadays, the need for new dietary containing some bioactive peptides with specific amino acid sequences increased to express biological functions. We investigated the hypocholesterolemic effect and ACE-inhibiting activity of bovine casein hydrolysates with different molecular weights. The bovine casein was hydrolysed with trypsin for different amounts of time to release bioactive peptides from the casein. Then, crude casein hydrolysate was ultrafiltered using membranes with two different molecularweight cut offs $(1 \mathrm{kDa}$ and $10 \mathrm{kDa})$ to determine the hypocholesterolemic effects and ACE-inhibiting activities of peptides with different molecular weights. The results showed that a higher level of hydrolysis (more active bioactive peptides) was associated with greater hypocholesterolemic and ACE-inhibiting effects in all the tested samples. The unhydrolysed crude casein reduced the cholesterol level in ortho-phthaldialdehyde (OPA) assays by $39.5 \%$, while the $10 \mathrm{kDa}$ and $1 \mathrm{kDa}$ permeates of casein hydrolysed with trypsin for $4 \mathrm{~h}$ reduced the cholesterol level by 50.7 and $69.6 \%$, respectively. The unhydrolysed crude casein and the $10 \mathrm{kDa}$ and $1 \mathrm{kDa}$ permeates of casein hydrolysed by trypsin for $4 \mathrm{~h}$ inhibited ACE activity by $18.9 \%, 29.7 \%$, and $51.4 \%$, respectively.
\end{abstract}

Keywords: bovine casein hydrolysate, trypsin enzyme, bioactive peptides, hypocholesterolemic, ace inhibitory
Volume 5 Issue 4 - 2016

\author{
Alhaj OA,' Irshad 1,2 Kanekanian AD² \\ 'Department of Food Science and Nutrition, King Saud \\ University, Saudi Arabia \\ ${ }^{2}$ Cardiff School of Health Sciences, Cardiff Metropolitan \\ University, UK
}

\begin{abstract}
Correspondence: Alhaj OA, Department of Food Science and Nutrition, College of Food and Agricultural Sciences, King Saud University, P.O. Box 2460, Riyadh I I45I, Saudi Arabia, Email mary.oalhaj@ksu.edu.sa
\end{abstract}

Received: October 18, 2016 | Published: December 02, 2016

\section{Introduction}

Coronary heart disease is one of the leading causes of death in the United States, Japan, and the European Union. ${ }^{1}$ Nearly $30 \%$ of the population of Britain suffers from moderately high cholesterol levels. An effective approach to reduce cholesterol levels would likely have a significant effect on coronary heart disease-related mortalities. The use of drugs is an expensive exercise and often entails unwanted side effects. Therefore, some researchers have sought dietary solutions that could be used in lieu of drugs. It was reported that food products containing angiotensin converting enzyme (ACE) peptides played a role in treating mild hypertension. ${ }^{2}$ Similarly, the consumption of a diet low in fat and saturated fatty acids has shown effectiveness in reducing blood cholesterol levels. Poor consumer satisfaction with low-fat diets has, however, resulted in further efforts to find other dietary solutions that could effectively reduce cholesterol levels. ${ }^{3}$ Various food commodities have been examined, including milk proteins, which have shown antithrombotic activities in animal trials. ${ }^{4}$ Casein is more susceptible than whey proteins to proteolysis because of its open and flexible structure. ${ }^{5}$ The degree of hydrolysis and the enzyme used for hydrolysis are crucial in determining the functional products of the hydrolysis. ${ }^{6}$ Controlled enzymatic hydrolysis reportedly improved the functional properties of casein. ${ }^{7}$ The ability of hydrolysed casein to reduce cholesterol levels has been hypothesised to be due to the direct interaction of Arg and Tyr with cholesterol, forming cholesterol apoprotein complexes. ${ }^{8}$ On the other hand, ACE inhibitors, including milk peptides, decrease the conversion of angiotensin I to angiotensin II, which leads to a decrease in bradykinin metabolism and, consequently, a decrease in arterial blood pressure. We aimed to investigate the hypocholesterolemic effect and ACE- inhibiting activity of bovine casein hydrolysates with different molecular weights.

\section{Materials and methods}

\section{Materials}

Bovine sodium caseinate, trypsin, 0-phthalaldehyde reagent, trifluroacetic acid (TFA), cholesterol, potassium hydroxide, n-hexane, ß- cyclodextrin, sulphuric acid, sodium hydroxide, hydrochloric acid, boric acid, sodium chloride, ACE, Hip-His-Leu, and ethyl acetate were purchased from Sigma Aldrich (U.K.). HPLC water, ethanol, and acetonitrile (ACN) were purchased from Fisher Scientific (U.K.). Ultrafiltration cells and Diaflo Ultrafiltration Membranes of $10 \mathrm{kDa}$ and $1 \mathrm{kDa}$ were purchased from Amicon Inc. The bicinchoninic acid (BCA) kit was purchased from Pierce (USA).

\section{Bovine casein hydrolysis using proteolytic enzymes}

Bovine casein solution was hydrolysed by trypsin for $4 \mathrm{~h}$ at a ratio of 1:100. Throughout the experiment, the solution temperature and $\mathrm{pH}$ were maintained at $37^{\circ} \mathrm{C}$ and 7.5 , respectively. The trypsin was inactivated by thermal treatment in a water bath for $5-6 \mathrm{~min}$ at $90^{\circ} \mathrm{C}$. All samples were kept at $-22^{\circ} \mathrm{C}$ in a freezer prior to further treatment.

\section{Determination of the level of protein hydrolysis}

The ortho-phthaldialdehyde (OPA) method a rapid, sensitive, and convenient spectrophotometric assay-was used to determine the degree of hydrolysis. The absorbance of samples was measured spectrophotometrically at $340 \mathrm{~nm}$ as described by Church et al., ${ }^{9}$ and modified by Alhaj et al., ${ }^{10}$ 
The degree of hydrolysis was determined using the following equation:

$$
\% \text { ACE inhibition } \frac{S-C}{D} \times 100
$$

where $\mathrm{S}$ is the hydrolysed sample reading formed by trypsin, $\mathrm{C}$ is the unhydrolysed sample reading as a control, and $\mathrm{D}$ is the difference in absorbance between the sample reading after $4 \mathrm{~h}$ (taken as $100 \%$ hydrolysis) and the unhydrolysed sample reading at $0 \mathrm{~h}$ (taken as $0 \%$ hydrolysis).

\section{Ultrafiltration of bovine casein hydrolysate and standardisation of protein concentration}

Crude samples of casein hydrolysates were ultrafiltered using an ultrafiltration unit (Amicon) fitted with Diaflo Ultrafiltration Membranes of $1 \mathrm{kDa}$ and $10 \mathrm{kDa}$. The ultrafiltration cell was operated under a pressure of 55 psi imposed by nitrogen gas. The collected crude permeates $(1 \mathrm{kDa}$ and $10 \mathrm{kDa})$ were freeze-dried using a freeze dryer (Savant MicroModulyo) and stored at $-22^{\circ} \mathrm{C}$. The protein concentrations of the crude casein and permeates were determined using the bicinchoninic acid (BCA) protein assay kit. All samples were standardised to a concentration of $10 \mathrm{mg} / \mathrm{mL}$ using doubledistilled water

\section{Reverse-phase high-performance liquid chromatography (RP-HPLC) profile of the casein peptides}

The collected permeates of hydrolysed and unhydrolysed casein were fractionated by RP-HPLC using an Agilent Technologies 1200 Series system with a C18 column $(250 \mathrm{~mm} \times 7.75 \mathrm{~mm}, 300 \AA$, ACE, Hichrom LTD, UK) at a controlled temperature of $21.5^{\circ} \mathrm{C}$. The peptides were eluted by gradient elution with solvent A for $3 \mathrm{~min}$, followed by a linear gradient of solvent B from $0 \%$ to $60 \%$ for $80 \mathrm{~min}$, and finally $100 \%$ solvent B for $10 \mathrm{~min}$. Solvent A comprised $95 \%$ water and 5\% ACN containing 0.1\% TFA; solvent B comprised $85 \%$ $\mathrm{ACN}$ and $15 \%$ water containing $0.1 \%$ TFA. The peptides were eluted at a flow rate of $1 \mathrm{ml} / \mathrm{min}$. Absorbance was measured at $220 \mathrm{~nm}$.

\section{Evaluation of the cholesterol-reducing effects of the bioactive peptides derived from the bovine casein hydrolysate fractions}

A method described by Rudel and Morris ${ }^{11}$ and modified by Mishra and Prasad ${ }^{12}$ was followed to determine the ability of the crude casein and the casein hydrolysate to reduce the cholesterol level. Cholesterol solution was prepared by dissolving cholesterol in $\beta$-cyclodextrin at a concentration of $1.5 \mathrm{mg} / 85 \mu \mathrm{L}$. An aliquot of $85 \mu \mathrm{L}$ cholesterol solution was transferred into each test tube and $100 \mu \mathrm{L}$ of each sample was added accordingly. After incubating samples for $1.5 \mathrm{~h}$ in water bath at $40^{\circ} \mathrm{C}, 1.5 \mathrm{~mL}$ of $95 \%$ ethanol followed by $1 \mathrm{~mL} 33 \% \mathrm{KOH}$ were added. $\mathrm{n}$-hexane was added to the mixture, then $1.25 \mathrm{~mL}$ of hexane top layer was transferred into new clean and dry test tubes then evaporated in water bath at $60^{\circ} \mathrm{C}$ under nitrogen gas. Dried residues were dissolved in $4 \mathrm{~mL}$ o-phthalaldehyde reagent (OPA), and then $2 \mathrm{~mL}$ of concentrated sulphuric acid was gently transferred. Absorbance was measured at 550nm using a spectrophotometer.

The percentage cholesterol reduction was calculated using the following equation:

$$
\% \text { Cholesterol reduction }=\left(\frac{C-S}{C}\right) \times 100
$$

Where, $\mathrm{C}$ is the average cholesterol reading for the unhydrolysed sample as a control, and $\mathrm{S}$ is the average cholesterol reading for the hydrolysed samples. The samples were: Blank (OPA + sulphuric acid), Control (dried residues of unhydrolysed sample + OPA + sulphuric acid), and Sample (dried residues of hydrolysed sample $+\mathrm{OPA}+$ sulphuric acid). All experiments were conducted in triplicate and analysed for standard deviation and $p$ value using QI Macros statistical software. All data was assumed to be normally distributed and results were deemed significant when $\mathrm{p}<0.05$ throughout.

\section{Determination of the ACE-inhibiting activity of the casein hydrolysates}

The method described by Pihlanto-Leppala ${ }^{13}$ was followed to determine ACE inhibition. An aliquot of $300 \mu \mathrm{L}$ of Hip-His-Leu added to each test tube, followed by the $50 \mu \mathrm{L}$ of sample at a concentration of $10 \mathrm{mg} / \mathrm{mL}$. Reaction was initiated by adding $6 \mu \mathrm{L}$ of $1 \mathrm{mU}$ ACE and incubated for $30 \mathrm{~min}$ at $37^{\circ} \mathrm{C}$. Reaction was stopped by adding $250 \mu \mathrm{L}$ of $1 \mathrm{M} \mathrm{HCL}$ followed by $1.7 \mathrm{~mL}$ of ethyl acetate. After mixing, $1.1 \mathrm{~mL}$ of upper ethyl acetate layer was transferred into clean dried test tubes, and then evaporated under nitrogen gas in water bath at $60^{\circ} \mathrm{C}$. Residues were dissolved in $1 \mathrm{~mL}$ deionised water, then absorbance was measured at $228 \mathrm{~nm}$ using a spectrophotometer. The ACE inhibition was measured using the following equation:

\section{$\% A C E$ inhibition $S-C D \times 100$}

Where $\mathrm{C}$ is the average absorbance reading of the unhydrolysed sample as a control, $\mathrm{S}$ is the average absorbance reading for the samples, and D is the difference in the average absorbance reading between the unhydrolysed and hydrolysed casein samples. The tested samples were: Blank (deionised water), Control: (dried residues of the Oh hydrolysis sample+deionised water), and Sample (dried residues of the $0.5 \mathrm{~h}, 1 \mathrm{~h}$, and $4 \mathrm{~h}$ hydrolysis samples+deionised water). All experiments were conducted in triplicate and analysed for standard deviation (SD) and $\mathrm{p}$ value using the QI Macros statistical software. All data was assumed to be normally distributed and results were deemed significant when $\mathrm{p}<0.02$ throughout.

\section{Results and discussion}

\section{Tryptic hydrolysis and the RP-HPLC profile of casein}

The overall amount of tryptic hydrolysis in the case in samples increased steadily over time. For the purpose of calculating the level of hydrolysis, the amount of hydrolysis measured at $4 \mathrm{~h}$ was taken as $100 \%$ hydrolysis Alhaj et al., ${ }^{10}$ even though not all of the protein in the sample was necessarily hydrolysed after $4 \mathrm{~h}$. Thus, the trypsin produced $73.3 \%$ hydrolysis in $30 \mathrm{~min}$ and $83.33 \%$ hydrolysis in $1 \mathrm{~h}$. Trypsin has specificity for Arg and Lys Antal et al., ${ }^{14}$ which account for about $12 \%$ of casein Belitz et al. ${ }^{15}$ The profile of the casein peptides was also determined by RP-HPLC to verify the hydrolysis capability of the trypsin. The chromatogram of unhydrolysed casein shown in Figure 1(A) has an elution of ca.14peaks at $0 \mathrm{~h}$ incubation. After $50 \mathrm{~min}$, all of the peptides except for two were eluted, indicating strong hydrophobicity. The chromatogram of casein after $30 \mathrm{~min}$ hydrolysis shown in Figure 1(B) has ca. 51peaks. Likewise, the chromatogram after $1 \mathrm{~h}$ hydrolysis shown in Figure 1(C) has ca. 51 peaks, although there is more hydrophilicity evident after $1 \mathrm{~h}$ hydrolysis than after 30 min hydrolysis. Similarly, the chromatogram after $4 \mathrm{~h}$ hydrolysis shown in Figure 1(D) has ca. 61 peaks, which indicates extensive hydrolysis. Thus, increased hydrolysis time was associated with the release of more peaks from the native protein. Compared with that of the peptides eluted from $30 \mathrm{~min}$ hydrolysis and $1 \mathrm{~h}$ hydrolysis, 
the retention time of the peptides eluted from $4 \mathrm{~h}$ hydrolysis was decreased, because all of the peptides were eluted before $67 \mathrm{~min}$. All of the above results reflect that the peaks with the maximum retention time, which are hydrophobic, were released at $0 \mathrm{~h}$ hydrolysis that the progress of the hydrolysis led to the release of more peptides with less retention time, which are more hydrophilic, and that the most hydrophilic peptides were released at $4 \mathrm{~h}$ hydrolysis. Zhong et al., ${ }^{16}$ determined the difference in hydrophobicity among Arg, Lys, Phe, Tyr, and Leu. Arg and Lys were found to be less hydrophobic than Phe, Tyr, and Leu. The hydrophobicity determined for Arg and Lys was 3.1 and 6.2, respectively, whereas that determined for Phe, Tyr, and Leu was 11.1, 12, and 11.1, respectively. Based on these results, the peptides released from casein by trypsin hydrolysis tended to be hydrophilic.

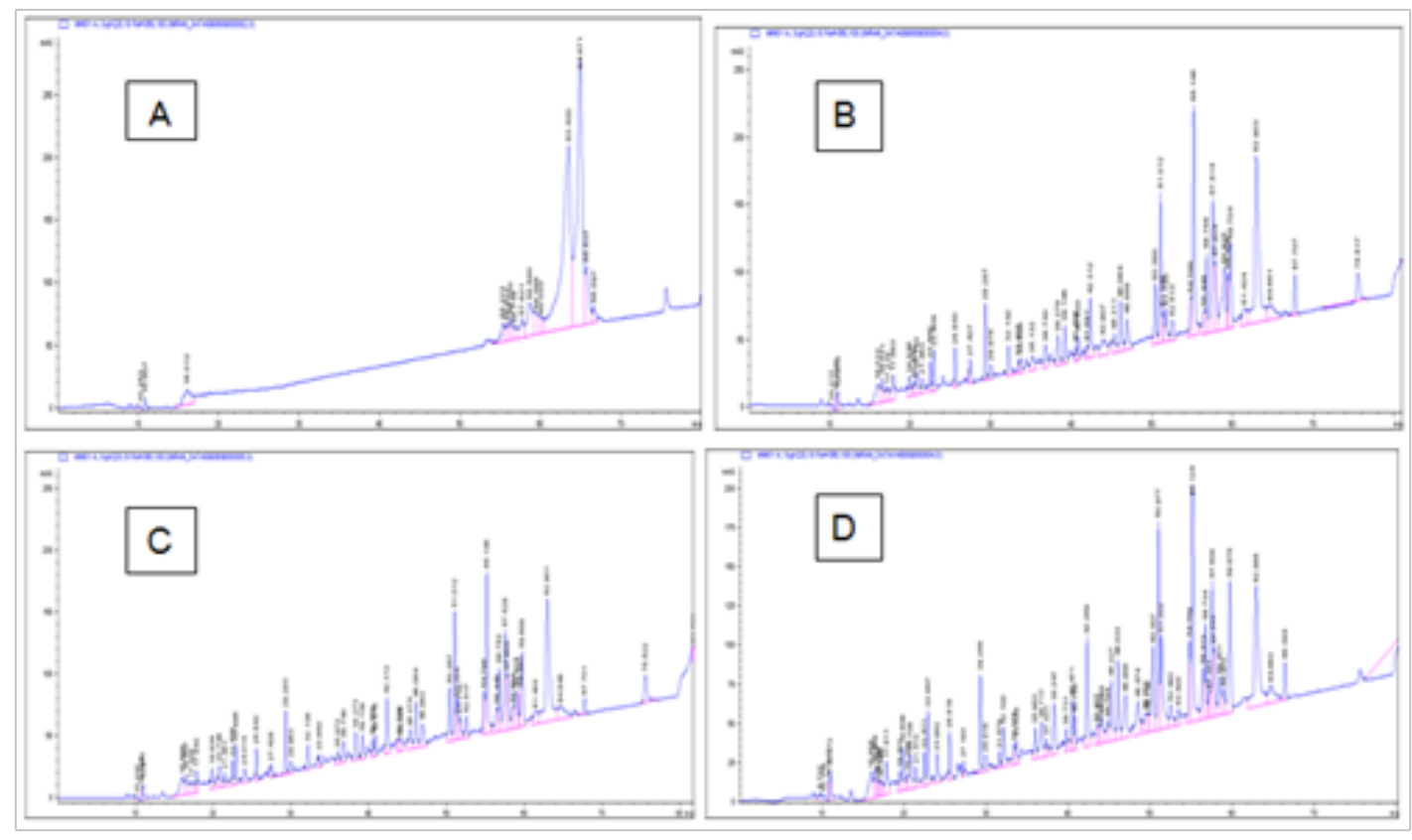

Figure I Qualitative RP-HPLC separation of bovine casein hydrolysed by trypsin for 0h (A), 0.5h (B), Ih (C), and 4h (D).

\section{Cholesterol-reducing activity of the casein hydrolysate} formed by trypsin

Figure 2 shows the cholesterol-reducing activity of the casein hydrolysates in the $1 \mathrm{KDa}$ and $10 \mathrm{KDa}$ permeates. There was a steady increase in the cholesterol-reducing activity over time, with significant differences among the crude casein, the $1 \mathrm{KDa}$ permeate, and the 10KDa permeate. Unhydrolysed crude casein showed 23.2\% cholesterol-reducing activity after 30min hydrolysis, which increased to $39.5 \%$ after $4 \mathrm{~h}$ hydrolysis due to the release of bioactive peptides by the enzymatic activities of contaminating bacteria in the raw milk Otte et al. ${ }^{17}$ or by the endogenous enzymes of the milk Gobbetti et al. ${ }^{18}$ On the other hand, the 10KDa permeate showed $44.9 \%$ cholesterolreducing activity after $30 \mathrm{~min}$ hydrolysis, which is almost a twofold increase relative to that of the unhydrolysed crude casein. After $4 \mathrm{~h}$ hydrolysis, the $10 \mathrm{kDa}$ permeate showed $50.7 \%$ cholesterol-reducing activity, which is significantly $(\mathrm{P}<0.05)$ higher than that of the unhydrolysed crude casein. These results are in agreement with the findings of Sugano et al., ${ }^{19}$ who showed that the hypocholesterolemic peptides of soybean protein had molecular masses of $1-10 \mathrm{kDa}$. In that case, the hypocholesterolemic properties of the peptides were attributed to the inhibition of cholesterol absorption and increases in the faecal excretion of steroidsmine \& Shahidi. ${ }^{20}$ The $1 \mathrm{kDa}$ permeate exhibited $55.1 \%$ cholesterol-reducing activity after $30 \mathrm{~min}$ hydrolysis, which is significantly $(\mathrm{P}<0.05)$ higher than that of the crude unhydrolysed casein $(23.2 \%)$ and that of the $10 \mathrm{kDa}$ permeate $(44.9 \%)$ after the same amount of time. After $4 \mathrm{~h}$ hydrolysis, the cholesterol- reducing activity of theKDa permeate increased to $69.6 \%$, which is also significantly $(\mathrm{P}<0.02)$ and higher than crude unhydrolysed casein and that of the $10 \mathrm{kDa}$ permeate after the same amount of time. Moreover, the cholesterol-reducing activity of the $1 \mathrm{kDa}$ permeate after 30min hydrolysis was higher than that of the unhydrolysed crude casein $(39.5 \%)$ and the $10 \mathrm{kDa}$ permeate $(50.7 \%)$ after $4 \mathrm{~h}$ hydrolysis. These results show that peptides with $1 \mathrm{kDa}$ molecular mass have more cholesterol-reducing activity than peptides with $10 \mathrm{kDa}$ molecular mass $(\mathrm{P}<0.05)$ and unhydrolysed crude casein $(\mathrm{P}<0.02)$. Our results are in agreement with those of Alhaj et al. ${ }^{10}$ who reported that peptides with molecular mass less than $1200 \mathrm{Da}$ are superior to large peptides in reducing cholesterol. Permeates of $1-10 \mathrm{kDa}$ are superior to unhydrolysed crude casein in reducing cholesterol, because small peptides are more easily absorbed into the intestine than large peptides, which makes them more effective in cholesterol reduction compared with the larger peptides Shah..$^{21}$ The cholesterolreducing activity of the $1 \mathrm{kDa}$ permeate is attributed to the high Arg and Lys content resulting from the trypsin hydrolysis Antal et al., ${ }^{15}$ The interaction between cholesterol and Arg was suggested to occur by hydrogen bonding between the hydroxyl groups of cholesterol and the guanidine groups of Arg residues Li et al., ${ }^{8}$ Likewise, the $\varepsilon$-amino groups of Lys are able to form hydrogen bonds with the hydroxyl groups of cholesterol. Thus, Arg can establish two hydrogen bonds per side chain, while Lys can establish one. Therefore, the bonding between cholesterol and Lys might not be as stable as that between cholesterol and Arg. 


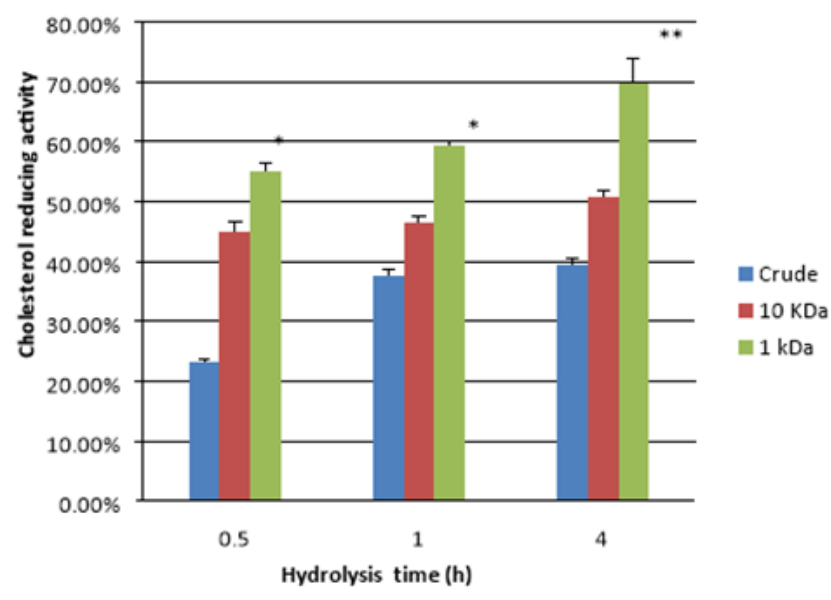

Figure 2 Cholesterol-reducing activity of unhydrolysed crude casein and of $10 \mathrm{kDa}$ permeate and $1 \mathrm{kDa}$ permeate of sodium caseinate $(10 \mathrm{mg} / \mathrm{mL})$ hydrolysed by trypsin at $37^{\circ} \mathrm{C}$ for up to $4 \mathrm{~h}$ at $\mathrm{pH} 7.5$ with an enzyme to substrate ratio of $\mathrm{I}: 100$. Error bars indicate the standard deviation. $\mathrm{n}=3$, ** $(\mathrm{P}<0.02)$, * $(\mathrm{P}<0.05)$.

\section{ACE-inhibiting activity of crude hydrolysates formed by trypsin}

The ACE-inhibiting activities differed significantly among unhydrolysed crude casein, the $10 \mathrm{KDa}$ permeate, and the $1 \mathrm{kDa}$ permeate (Figure 3). The unhydrolysed crude casein showed $13.5 \%$ ACE-inhibiting activity at $0.5 \mathrm{~h}$, which increased to $19 \%$ after $4 \mathrm{~h}$ of hydrolysis because of the production of ACE-inhibiting peptides by the enzymatic activities of contaminating bacteria in the raw milk Otte et al., ${ }^{17}$ or by the endogenous enzymes of the milk Gobbetti et al. ${ }^{18}$ The $0.5 \mathrm{~h}$ and $4 \mathrm{~h}$ tryptic hydrolysates of the $10 \mathrm{KDa}$ permeate showed $25.7 \%$ and $29.7 \%$ ACE inhibition, respectively. The $0.5 \mathrm{~h}$ and $4 \mathrm{~h}$ tryptic hydrolysates of the $1 \mathrm{kDa}$ permeate showed $34.4 \%$ and $51.4 \%$ ACE inhibition, respectively. These results clearly reflect that the ultrafiltration treatment of the crude hydrolysate isolated the peptides with higher ACE-inhibiting activity. It has been reported that the ultrafiltration of the thermolysin hydrolysis products of bonito increased the ACE-inhibiting activity by two fold Fujita et al., ${ }^{22}$ Our results show that the $10 \mathrm{KD}$ a permeate exhibited better ACE inhibition than the unhydrolysed crude casein, while the $1 \mathrm{kD}$ a permeate exhibited better ACE inhibition than the $10 \mathrm{kDa}$ permeate. In a similar study, sodium caseinate was hydrolysed using trypsin and Bifidobacterium animalis subsp. Lactis (Bb-12) separately Alhaj. ${ }^{23}$ The fractions with the lowest molecular weights exhibited the greatest ACE inhibition, and the molecular masses of the ACE-inhibiting peptides were less than $1 \mathrm{kDa}$. The reason for the ACE inhibition might be attributed to the purification of specific peptides that have exposed Arg and Lys residues. Antal et al., ${ }^{14}$ expressed the similar view that trypsin has a cleaving specificity towards Arg and Lys. So it could be assumed that among the released terminal amino acids, Arg and Lys were involved in the ACE inhibition. It has been reported that positively charged amino acids at the ultimate $\mathrm{C}$-terminal position such as $\mathrm{Arg}$ (guanidine group) and Lys ( $\varepsilon$-amino group) appear to effectively inhibit ACE Li et al., ${ }^{24}$

Chobert et al., ${ }^{25}$ found that the ACE-inhibiting activity of tryptic hydrolysates of ovine $\beta$-lactoglobulin increased with the degree of hydrolysis. In another study, Qula milk casein was hydrolysed for $60,120,180,240,300$, and $360 \mathrm{~min}$ using alcalase. The $240 \mathrm{~min}(4 \mathrm{~h})$ hydrolysate showed the greatest ACE inhibition. The hydrolysates were fractionated using ultrafiltration, and two novel ACE-inhibiting peptides with respective molecular masses of 550Da and 566.4Da were identified Mao et al., ${ }^{26}$ These results clearly reflect that hydrolysis improved and enhanced the ACE-inhibiting activity and that the degree of hydrolysis has a positive correlation with ACE inhibition. Moreover, the use of ultrafiltration isolated the fractions that exhibited higher ACE inhibition activity than the crude hydrolysates.

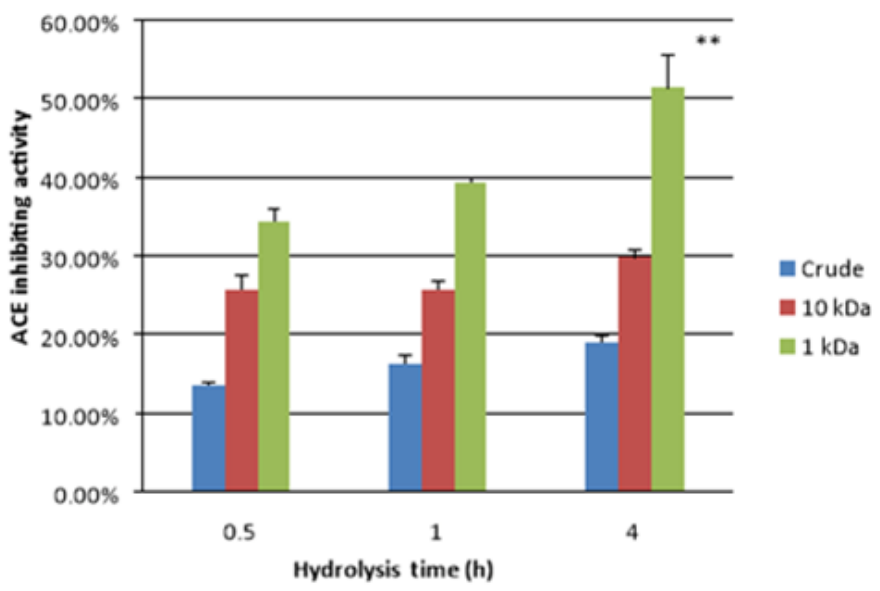

Figure 3 ACE-inhibiting activity of unhydrolysed crude casein and of $10 \mathrm{kDa}$ permeate and I kDa permeate of sodium caseinate $(10 \mathrm{mg} / \mathrm{mL})$ hydrolysed by trypsin at $37^{\circ} \mathrm{C}$ for $4 \mathrm{~h}$ at $\mathrm{pH} 7.5$ with an enzyme to substrate ratio of I: 100 . Error bars indicate the standard deviation. $\mathrm{n}=3 * *,(\mathrm{P}<0.002)$.

\section{Conclusion}

Our results show that unhydrolysed crude casein reduces cholesterol and ACE-inhibiting activity by up to $39.5 \%$ and $19 \%$, respectively. Tryptic hydrolysis improves and enhances the cholesterol-reducing and ACE-inhibiting activity to up $69.6 \%$ and $51.4 \%$, respectively. Moreover, the use of ultrafiltration fitted with $1 \mathrm{KDa}$ and $10 \mathrm{KDa}$ cut off membranes resulted in more functional properties than did the use of crude unhydrolysed casein. The peptides with molecular mass less than $1 \mathrm{KDa}$ had the maximum potential for cholesterol reduction and ACE-inhibiting activity. The stability of the bioactive proteolytic fractions in the pilot-scale processing and manufacturing of products need to be evaluated.

\section{Acknowledgements}

None.

\section{Conflict of interest}

Author declares that there is no conflict of interest.

\section{References}

1. Masayuki Y. Regulation of cholesterol biosynthesis and absorption: Ultimate management of dyslipidemia with statin and ezetimibe. Medicinal Chemistry. 2008;16(4):177-182.

2. Unger T. The role of the renin-angiotensin system in the development of cardiovascular disease. Am J Cardiol. 2002;89(2A):3A-9A.

3. Taylor GRJ, Williams CM. Effects of probiotics and prebiotics on blood lipids. Br J Nutr. 1998;80(4):S225-S230.

4. Chabance B, Marteau P, Rambaud JC, et al. Casein peptide release and passage to the blood in humans during digestion of milk or yogurt. Biochimie. 1998;80(2):155-165. 
5. Guo MR, Fox PF, Flynn A, et al. Susceptibility of $\beta$-lactoglobulin and Na-Caseinate to proteolysis of pepsin and trypsin. J Dairy Sci. 1995;78(11):2336-2344.

6. Abert T, Kneifel W. Physicochemical and functional properties of casein hydrolysates as obtained by treatment with different enzymes. In: Protein and fat globule modifications by heat treatment, homogenization and other technological means for high quality dairy products. Intl Dairy Federation Spec 9303. 1992. p. 125-131.

7. Leonil J, Molle D, Maubois JL. Study of the early stages of tryptic hydrolysis of beta casein. Le Lait. 1988;68:281-294.

8. Li H, Yao, Z-X, Degenhardt B, Teper G, et al. Cholesterol binding at the cholesterol recognition/interaction amino acid consensus (CRAC) of the peripheral type benzodiazepine receptor and inhibition of steroidogenesis by an HIV TAT-CRAC peptide. Proceedings of the National Academy of Sciences. 2001;98:267-1272.

9. Church FC, Swaisgood HE, Porter DH, Spectrophotometric assay using $o$-Phthaldialdehyde for determination of proteolysis in milk and isolated milk proteins. J Dairy Sci. 1983;66(6):1219-1227.

10. Alhaj OA, Kanekanian AD, Peters A, et al. Hypocholesterolemic Effect of Bifidobacterium animalis Subspecies. Lactis (Bb12) and Trypsin Casein Hydrolysate. Food Chemistry. 2010.123:430-435.

11. Rudel LL, Morris MD. Determination of cholesterol using o-phthalaldehyde. J Lipid Res. 1973;14(3):364-366.

12. Mishra V, Prasad DN. Application of in vitro methods for selection of Lactobacillus casei strains as potential probiotics. Int J Food Microbiol. 2005;103(1):109-115.

13. Pihlanto-Leppala A, Rokka TH, Korhonen H. Angiotensin I converting enzyme inhibitory peptides derived from bovine milk proteins. International Dairy Journal. 1998;8(4):325-331.

14. Antal J, Pal G, Asboth B, et al. Specificity assay of serine proteinases by reverse phase high performance liquid chromatography analysis of competing oligopeptide substrate library. Analytical Biochemistry. 2001;288(1):156-167.

15. Belitz HD, Grosch W, Schieberle P. Food Chemistry. Berlin, Germany: Spring; 2009. 291p
16. Zhong F, Xiaomei Z, Ma J, et al. Fractionation and identification of a novel hypocholesterolemic peptide derived from soy protein Alcalase hydrolysates. Food Research International. 2007;40(6):756-762.

17. Otte J, Shalaby SM, Zakora M, et al. Angiotensin converting enzyme inhibitory activity of milk protein hydrolysates: Effect of substrate, enzyme and time of hydrolysis. International Dairy Journal. 2007;17(5):488-503.

18. Gobbetti M, Minervini F, Rizzello CG. Angiotensin I-converting enzyme inhibitory and antimicrobial bioactive peptides. Int $J$ Dairy Technol. 2004;57:172-188.

19. Sugano M, Goto S, YamadaY, et al. Cholesterol lowering activity of various undigested fractions of soybean protein in rat. $J$ Nutr 1990;120(9):977-985.

20. Mine Y, Shahidi F. Nutraceutical Proteins and Peptides in Health and Disease. CRC Press (Taylor and Francis Group); 2006:41-60.

21. Shah NP. Effects of milk-derived bioactivities: an overview. Br J Nutr. 2000;84(Suppl 1):3-10.

22. Fujita H, Yokoyama K, Yoshikawa M. Classification and antihypertensive activity of angiotensin I -converting enzyme inhibitory peptides derived from food proteins. Journal of Food Science. 2000;65(4):564-569.

23. Al-Haj OA. The effect of casein hydrolstae formed by trypsin or Bifidobacterium Animalis subsp. Lactis (Bb-12) culture on cholesterol and angiotensin converting enzyme $(A C E)$ inhibition. University of Wales Institute, UK; 2008. p. 116-132.

24. Li GH, Le GW, Shi YH, et al. Angiotensin I-converting enzyme inhibitory peptides derived from food proteins and their physiological and pharmacological effects. Nutrition Research. 2004;24(7):469-486.

25. Chobert JM, El-Zahar K, Sitohy M, et al. Angiotensin I-converting enzyme (ACE) inhibitory activity of tryptic peptides of ovine $\beta$-lactoglobulin and of milk yoghurts obtained by using different starters. Lait. 2005;85(3):141-152.

26. Mao XY, Ni JR, Sun WL, et al. Value-added utilization of yak milk casein for the production of angiotensin-I-converting enzyme inhibitory peptides. Food Chemistry. 2007;103(4):1282-1287. 